\title{
Costal Cartilage
}

National Cancer Institute

\section{Source}

National Cancer Institute. Costal Cartilage. NCI Thesaurus. Code C32391.

The cartilage positioned between the anterior end of the rib and the sternum. Its elasticity allows the ribcage to expand while breathing. 